\title{
Proteção social e seguridade social no Brasil: pautas para o trabalho do assistente social*
}

\author{
Social protection and social security in Brazil: \\ agenda for the social worker's work
}

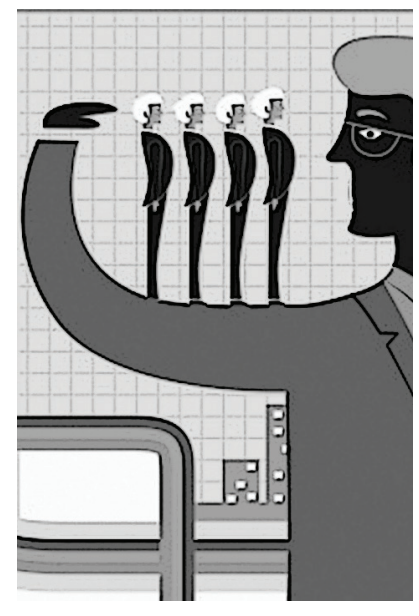

Aldaíza Sposati**

Resumo: Este artigo particulariza a relação de confronto da política pública de proteção social aos valores da sociedade do capital. Sua ação preventiva e restaurativa, face a necessidades de dependência, fragilidade, vitimização, encontra empecilhos à completude da atenção, ao exercício do controle social, à plena responsabilidade pública. $\mathrm{O}$ profissional do Serviço Social orbita esse complexo movimento que, paradoxalmente, opera barreiras de acesso a direitos de proteção social.

Palavras chaves: Proteção social. Seguridade Social. Serviço Social. Direitos de proteção. Incompletudes da proteção social.

\begin{abstract}
This article particularizes the confrontation between the public policy of social protection and the values of the capital society. Due to necessities related to dependence, fragility and victimization, its preventive and restorative action finds obstacles to complete attention, to exercise social control and to assign whole public responsibility. The social worker moves around this complex field that paradoxically operates barriers of access for social protection rights.
\end{abstract}

Keywords: Social protection. Social segurity. Social Service. Protection rights. Social protection incompleteness.

* Reflexão apresentada originalmente no $6^{\circ}$ Seminário Anual de Serviço Social promovido pela Cortez Editora, em São Paulo, em 13 de maio de 2013.

** Professora titular da PUC-SP, São Paulo, Brasil. Coordenadora do Núcleo de Estudos e Pesquisas em Seguridade e Assistência Social — NEPSAS do Programa de Estudos Pós-graduados em Serviço Social. E-mail: aldaiza@sposati.com.br. 


\section{Introdução}

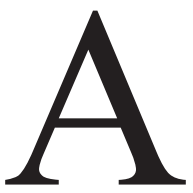

nalisar, pesquisar, refletir, desenvolver trabalho profissional no campo da proteção social e no âmbito de uma sociedade do capital exige, à partida, ter presente que a leitura crítica aponta que esse ambiente é marcado por paradoxos e contradições que se expressam por formas variadas, entre as quais, por mais incoerente que possa parecer, a reiteração da desproteção social.

A proteção social, política pública de forte calibre humano, carrega marca genética que a torna um tanto distinta de outras políticas sociais. Seu campo de ação não se refere, propriamente, à provisão de condições de reprodução social para restauração da força viva de trabalho humano. As atenções que produz constituem respostas a necessidades de dependência, fragilidade, vitimização de demanda universal porque próprias da condição humana. Porém, o modo pelo qual essa demanda é reconhecida e incorporada, as respostas que obtém, no âmbito público ou privado, decorrem de valores, mais, ou menos, igualitários da sociedade para com seus cidadãos.

Relembra-se de saída o que já se sabe: o trato da proteção social em sua forma de previdência social é, no caso brasileiro, um mosaico de respostas desiguais a partir do vínculo formal do trabalhador, e não só de sua remuneração. Essas desigualdades são reproduzidas inclusive, ou sobretudo, no trato de benefícios de idêntica natureza, como a aposentadoria. Embora seja universal o alcance do piso de um salário mínimo para todos os aposentados, é só nessa condição de valor inicial, ou mais baixo, que o princípio genérico da igualdade de trato se expressa. Caso fosse possível detectar, no emaranhado de regulações particularizadas, os valores mais altos de aposentadoria, a primeira pista seria buscar sua ancoragem na condição de exercício de função pública, e ali não seria obra de ficção encontrar brasileiros acima de 60 anos recebendo mensalmente como proteção social estatal valor cerca de 100 vezes maior do que um salário mínimo.

O parágrafo acima é múltiplo em apontar idiossincrasias em respostas institucionais, sobretudo públicas, que, contraditoriamente, ferem princípios igualitários da seguridade social. Permite assinalar outro traço no conjunto de dispositivos: o sentido de igualdade é aplicado nos valores de piso que são estritamente vigiados; por sua vez, os limites de teto permanecem " transgredidos sob a ordem", uma vez que são acatadas justificativas de amparo legal em conformidade com a interpreta- 
ção de dispositivos. Se cabe flexibilidade para ampliar os valores mais altos, os pisos são inflexíveis, mesmo que comprovada a presença da situação de necessidade. Enquanto a vantagem alcança o estatuto legal e aplicação do princípio de equidade, que permite o exercício da justiça pela incorporação do respeito à diferença, a necessidade é dada como homogênea e o piso não comporta equidade.

Uma das expressões mais perversas do exercício segregado da complacência com os de maior ganho permanece sob a vigilância do INSS. Embora benefício de assistência social, isto é, não referido ao seguro social, a inflexibilidade de trato no acesso ao BPC - Benefício de Prestação Continuada, direcionado a pessoas com deficiência (desde a primeira infância), é operada por "tripla barreira":! o requerente não pode alcançar o per capita de renda familiar de um quarto do salário mínimo; o requerente não pode ter outro membro da família com benefício, pois ele será considerado no cálculo do per capita (o que não ocorre com idosos); o requerente deverá mostrar que sua deficiência é durável, isto é, permanecerá após dois anos. Ao que parece, faltou considerar que viver dois anos sob fragilidade não só agudiza a deficiência como pode ampliar a perecibilidade da própria vida.

$\mathrm{O}$ vínculo da proteção social com períodos do ciclo de vida humano em que é incompatível, ou de reduzidas condições, a inserção no mercado de trabalho de forma a possibilitar a automanutenção do indivíduo pelo desempenho do trabalho vivo inscreve-a a princípio na condição de transgressora de regras constituintes da acumulação do capital. Mas, como se relembrou parágrafos acima, estratégias reguladoras podem moldar o formato da proteção social, funcionalizando-a não só aos interesses da acumulação como a reprodução de desigualdades, embora uma e outra se acompanhem.

A hipótese em que a reflexão deste artigo se move parte da seguinte consideração: a proteção social na sociedade do capital, exatamente por atuar com "indivíduos" sem interesse imediato para o processo de acumulação, porque afastados da inserção no trabalho vivo, contaria com menos interferência de interesses econômicos do capital; todavia, não é isso que ocorre de fato. Pelo contrário, as atenções de proteção social, os dispositivos e regras que a regem, sua gestão e processos de trabalho são submetidos a múltiplas racionalidades geradoras de formas truncadas, parciais, desarticuladas de respostas às desproteções sociais.

1. Embora se entenda que o trato da deficiência seja exatamente a remoção de barreiras, pois estas dificultam sua possível mobilidade, interferindo no exercício de sua possível autonomia. 
Esse processo, marcado por interrupções, intervalos, incompletudes, ao contrário de configurar uma irracionalidade, expressa sim uma forma estratégica em manter o campo da proteção social com baixa estabilidade, de modo a que, mais facilmente, possa sofrer ajustes sob crises conjunturais ou estruturais do capital. Outra face desse processo estratégico consiste em manter capacidade para reproduzir, com mais celeridade, a desigualdade que distingue os brasileiros entre si e impede a afirmação da universalidade da cidadania.

Essa afirmação é de simples observação empírica. Na ocorrência de crise do capital, uma das primeiras contenções é a introdução de medidas de arrocho nas atenções de proteção social ou no sistema de proteção social. Destaca-se essa medida dentre aquelas de enfrentamento da crise mundial pelos países da Comunidade Europeia.

A decodificação dessas "racionalidades", que geram barreiras à universalização da proteção social como direito são tomadas nesta reflexão como possibilidade de "ocupação profissional de resistência ético-política" pela possibilidade que contem para articulação de Direitos Humanos e sociais e espaço de reconhecimento de cidadania.

O "campo de confronto" na seguridade social no Brasil se concretiza no ambiente de três políticas sociais que lhe foram constitucionalmente subordinadas: previdência social, saúde e assistência social. Tratam-se de políticas com capilaridade, disseminadas em todo o território nacional, ainda que em padrões diversos, que contem espaço de exercício de profissionais, entre os quais, o assistente social.

A perspectiva da "ocupação profissional de resistência ético-política", que aqui se coloca para reflexão, não flui da elevação idealizada da potência de uma política social face ao modelo econômico político de uma sociedade do capital. Não flui também de um idealismo de uma profissão, nem da ausência de crítica às regulações da proteção social na sociedade brasileira. Ela é somente coerente com o reconhecimento do campo de tensão em que se dá o exercício do profissional assistente social e que este, para além da análise crítica, deve estar qualificado para a ação, sem que isso seja considerado como uma adesão ao processo de exploração ou a construção de um novo fetiche do capital face ao trabalhador.

Os movimentos de junho mostraram o efeito repressor e paralisante do gás de pimenta, mas mostraram também, que ele não desmobiliza a manifestação pois até permite conhecer e disseminar o uso de seu antídoto, o vinagre, ingrediente do simples cotidiano. 


\section{Breve caracterização de algumas irracionalidades}

Os indivíduos considerados improdutivos para o capital é que inserem suas necessidades no âmbito da proteção social. A lógica da sociedade do capital é antagônica à proteção social por considerá-la expressão de dependência, e atribui às suas ações o contorno de manifestação de tutela e assistencialismo, em contraponto a liberdade e autonomia que, pelos valores da sociedade do capital, devem ser exercidas pelo "indivíduo" estimulando sua competição e desafio empreendedor. Nesse ambiente, a proteção social é estigmatizada no conjunto da ação estatal e, por consequência, esse estigma se espraia àqueles que usam de suas atenções e, até mesmo, a quem nela trabalha.

Demandatários de proteção social são nominados por inválidos uma vez que, para o capital não são contáveis seu autossustento não é mantido pelo salário advindo da ocupação, emprego ou trabalho.

A inflexão em tratar a proteção social em condição distinta das demais políticas sociais é aplicada por economistas que se ocupam da análise de fontes de custeio de políticas sociais. A distinção da proteção social no âmbito das políticas sociais se apoia na particularidade de seu financiamento constituído por fontes de procedências diferenciadas.

A previdência social é cofinanciada por agentes privados, entre eles o próprio trabalhador e o seu contratante, e pelo agente público que a subsidia. O pagamento do salário-família na proteção social contributiva mantém um ritual de procedimentos que permite que se desconheça quantas e quem são as crianças até 14 anos que ele inclui. $\mathrm{O}$ empregador paga, em folha de sua empresa, o salário-família relativo aos filhos do empregado; a seguir, é ressarcido pela Previdência Social que considera o montante pago pelo empregador como "adiantamento" do mensal da cota patronal.

Confinado a um procedimento contábil, a previdência não sabe informar nada sobre as crianças que recebem salário-família. Submetido a contínuo arrocho, o valor desse benefício não só deixou de ser universal como vem sendo submetido a critérios de residualidade. Em 2013, quando o salário mínimo nacional foi fixado em $R \$ 678,00$, o valor do salário-família foi fixado em $R \$ 33,16$ por filho, cujos pais ganhem até $\mathrm{R} \$ 646,55$ e $\mathrm{R} \$ 23,36$ quando os pais ganhem entre $\mathrm{R} \$ 646,56$ a $\mathrm{R} \$ 971,78$. Esses benefícios alcançam crianças até 14 anos ou inválidas. O Programa Bolsa Família atribui mensalmente para famílias com renda per capita até 
$\mathrm{R} \$ 140,00$ benefício individual de $\mathrm{R} \$ 32,00$ para até 5 crianças de 0 a 15 anos, e $\mathrm{R} \$ 38,00$ para até 2 adolescentes de 16 a 17 anos por família. Como se pode perceber, o Programa Bolsa Família é um tanto mais generoso com crianças e adolescentes em valor de benefício, embora o salário-família ainda seja menos restritivo na inclusão pela renda familiar. Enquanto o monitoramento da criança no Bolsa Família é de forte incidência, pois se ela não for à escola sua família perde o benefício, nada se sabe da criança que recebe o salário-família, se estuda ou é analfabeta.

Deve-se ter presente que se está tratando de dois benefícios para mesma criança brasileira e sob a mesma égide da proteção social ou do direito à seguridade social. Qual a motivação da discrepância? Um se refere ao campo contributivo do seguro social e outro não? O direito das crianças e dos adolescentes, seres em desenvolvimento que devem receber proteção integral, está sendo respeitado? Há algum motivo para a ausência de manifestação sobre essa desigualdade pelos conselhos de defesa de direitos da criança e do adolescente?

Há a permanência da taxa de contribuição do trabalhador, uma exigência moral, mesmo quando seu contratante, o empresário, é isentado do pagamento como forma de subsídio estatal à sua produção privada e obtenção de lucro pessoal. O impacto desse ajuste econômico estatal no padrão da aposentadoria do trabalhador, ou o caráter do benefício que, no futuro, lhe vai ser assegurado não transparece ou não se materializa como parte do ajuste econômico do empresário; pelo contrário, é como se tal impacto não existisse ou não fosse ocorrer.

Não foi esclarecido qual será o mecanismo a ser adotado para garantir a permanência do salário-família dos filhos de trabalhadores quando da ocorrência de isenção, da empresa que os contrata, do pagamento da cota patronal. ${ }^{2}$

Argumentos de corte liberal ou neoliberal partem da orientação de que é necessário - para favorecer a autoestima, a liberdade, a autonomia do indivíduo superar sua condição improdutiva de beneficiário, introduzindo no modelo de proteção social a disciplina de frequência a treinamentos para que se reduzam situações de dependência que requerem proteção e se ampliem oportunidades de "exercício de autonomia" isto é, ocupação remunerada de mão de obra, para que o beneficiário se transforme em provedor de sua própria proteção.

2. O sistema atual opera por ressarcimento, considerando o valor pago em salário-família como adiantamento da cota patronal a ser paga pelo empresário que agora ficou isento. 
O requerente de proteção social deve pagar o seguro, deve ser treinado para exercer alguma ocupação rentável, deve se submeter a um processo socioeducativo pautado no domínio de procedimentos ocupacionais como cursos de docinhos, salgadinhos, pizza, manicure, depilação, entre outros, pois nesse modo de pensar a proteção advém não de relações e vínculos mas de condições individuais de ativação. A orientação é a de que o beneficiário possa se tornar um empreendedor e "ganhar sua emancipação". Nesse horizonte liberal, a perspectiva da proteção social é tornar-se o mais reduzida possível e contrapor a "dependência com a condição de ser consumidor".

É a condição de mix público-privado que dá plena acolhida ao formato tripartite do financiamento do seguro social público, pois o seu possível usuário deve pagar de forma regular e antecipada sua cota, mas não terá direitos similares ao do consumidor privado, sendo sujeitado a ter atenções bastante distintas daquelas que lhe foram apontadas ao se filiar ao seguro público sem ter porém direito a ressarcimento. ${ }^{3}$

Enquanto espécie distinta de política pública, a proteção social transita entre o campo público e o privado como se esse locus intermediário de difícil caracterização de responsabilidades para com a atenção a ser prestada fosse, na sociedade do capital, lugar compatível e aceitável à sua natureza de apoio a trabalhadores que não estão necessariamente em exercício do trabalho. São acolhidas nesse nicho difuso de responsabilidades entidades ou organizações sociais que se apresentem como não lucrativas e/ou de atenção gratuita, e mui raramente como coprodutoras de atenções na condição de direito social.

O lócus intermediário entre público e privado é de difícil caracterização quanto a responsabilidade para com a atenção a ser prestada e, por consequência, nele é difícil efetivar a obrigatoriedade da provisão de direitos. Esse assentamento da proteção social em terreno movediço torna frágil a efetivação do princípio da universalidade de atenção.

A previdência social se destina ao trabalhador formal. A assistência social tem operado de modo seletivo, aplicando teste de meios àqueles que demandam sua

3. Exemplos claros desta afirmação podem ser extraídos quer da introdução do fator previdenciário, que impregnou de aroma de calote àqueles que pagaram cotas de contribuição calculadas sobre a integralidade do salário, mas que ao se aposentar passam a receber valores sem qualquer compatibilidade com tais contribuições; ou ainda aos funcionários públicos que mesmo após aposentados são compelidos a permanecer recolhendo mensalmente a mesma taxa relativa à previdência sobre o valor da aposentadoria recebida. 
atenção. A saúde que, no caso brasileiro, tem contraparte na seguridade social, estabelece prioridades de atenção pelo risco da situação, cria filas de espera significativas ou agendamento com grandes intervalos de espera.

Percorre o ideário da proteção social referência negativa em relação à concessão de benefício ou de seu usufruto por longos períodos. Como forma de superação desse entendimento negativo, outra contracorrente afirma que o benefício deva ser superado pelo próprio trabalho daquele que é beneficiado.

Quando anteriormente foi apresentada a hipótese em que se assenta esta reflexão apontou-se para um conjunto de estratégias que passam a percorrer a política de proteção social de modo a torná-la menos inóspita aos interesses da sociedade capitalista. $\mathrm{Na}$ argumentação desenvolvida, algumas dessas racionalidades estratégicas foram sendo reveladas:

- não consolidação da responsabilidade estatal pelas ações de proteção social. É produto de racionalidade estratégica mantê-la sob um mix de responsabilidades entre o estatal e o privado;

- estratégias de gestão diversionistas fazem com que a responsabilidade estatal não se consolide ou, pelo menos, não se consolide plenamente, quer quanto à totalidade das obrigações, quer quanto à totalidade da demanda;

- introdução de procedimentos ativos de modo a provocar que o membro dependente da família se "autonomize" e se transforme em provedor de sua própria proteção;

- gestão da proteção social organizada sob ritmo protelatório, sem acesso aberto a conhecer a incidência de demandas com precisão e transparência de informação;

- fragmentação da gestão, da atenção e do alcance de respostas da proteção social;

- difusão de ideário que propõe a curta permanência na utilização de serviços, benefícios e demais atenções;

- financiamento centrado na oferta de proteção monetarizada em benefícios financeiros e de transferência de renda, enquanto meios de acesso ao mercado;

- forte variação de cobertura entre benefícios e serviços de proteção social;

- quanto mais pública ou estatal a política de proteção social se apresente mais se torna motivo de possível confronto social; 
- inexistência de referência alargada do que se quer como proteção social enquanto direito de cidadania e não só como proteção ao trabalho;

- fragmentação da proteção social em diferentes políticas sociais, implementadas a partir de seu horizonte particular desconectado de uma proposta de proteção social para a universalidade dos cidadãos brasileiros;

- incompletude da proteção social no Brasil é historicamente presente e se expressa sob diferentes e múltiplas formas.

As marcas de descontinuidade, não integralidade, fracionamento, não igualdade de acesso e de reconhecimento presentes na dinâmica da proteção social brasileira se expressam de múltiplas formas, estimulando que princípios como da distinção, da competição, do individualismo, invadam e se apropriem da proteção social. A fundamentação da proteção social em valores de solidariedade, ou do "solidarismo cidadão", firmados no reconhecimento horizontal de igualdade, é subsumida e submetida ao individualismo e fragmentação.

A institucionalização no Brasil da proteção social contributiva, no formato de seguro reconhecido como previdência social, tem quase um século de existência. Esse longo período não significa porém tempo de existência igualitária aos trabalhadores brasileiros, uma vez que ele é marcado por um processo de inclusão seletiva da força de trabalho formal. É só nesta segunda década do terceiro milênio que o trabalho exercido em ambiente doméstico está passando a ser reconhecido como formal e portador de direitos trabalhistas, antes facultativos, inclusive quanto ao acesso à proteção social pública.

O reconhecimento de direitos do trabalho no Brasil nunca foi uma condição a ele intrínseca, mas aderente ou adjetiva e, enquanto tal, objeto de regulações fragmentadas de incidência parcial a esta ou aquela categoria de ocupação de maior interesse conjuntural à produção econômica.

Esse caráter parcial e incompleto da proteção social contributiva brasileira, praticado por um século, longe de ser expressão de incapacidade gerencial, é de fato omissão consentida, portanto objeto de racionalidade, que estrategicamente impede o reconhecimento de todos os que estão na mesma condição, no caso a de trabalhador, usufruam da mesma identidade, do mesmo reconhecimento e dos mesmos direitos.

Para além do valor do salário, a submissão da proteção social a um formato meritocrático que seleciona a ocupação que vai ser, ou não, incluída no direito 
trabalhista a transforma em território de regulação econômica e não social. Essa transmutação é uma das possíveis estratégias, de caráter sutil, pelas quais o caráter antagônico da proteção social aos interesses do capital se manifesta.

A ideia/perspectiva social do Estado em financiar e desenvolver a proteção social não contributiva não é tão simples. A permanência da cultura da concessão para terceiros da operação dessas ações persiste em vários segmentos rejeitando que ela seja assumida como responsabilidade pública. Consideram isso uma forma de estatização e não confirmam a proteção de assistência social enquanto dever de Estado e direito de cidadania.

Nesse modo de ver e agir, o Estado não assume plenamente as atenções sociais, somente passa meios, em geral insuficientes, para as organizações sociais operarem como se fosse da iniciativa da sociedade e não do Estado tal atenção. Digamos que nesses casos não há o trânsito do serviço pela esfera pública; assim, ele não se constitui direito aos olhos do Estado. Ele tanto pode existir como não existir, pode atender um, e não atender a outro, ou outra. Não há responsabilidades ou obrigações claras com todos. Os agentes institucionais, de certo modo, se acostumaram a não enxergar a totalidade das atenções prestadas, uma vez que predomina o trabalho caso a caso, grupo a grupo, entidade a entidade, sem compromisso de direito com todos os cidadãos em igual situação.

O modelo brasileiro de proteção social não partiu do reconhecimento universal enquanto direito de todos os trabalhadores; sua lógica seletiva foi incluindo paulatinamente segmentos da força de trabalho ativa.

A perspectiva de universalidade da proteção social mostra-se como confronto com as regras do capital, da acumulação, pois confere significado de igualdade em uma sociedade que, pelas regras do mercado, é fundada na desigualdade. Esse confronto se manifesta em formas múltiplas e permanece presente em contínua luta.

Analisar os rumos da proteção social brasileira significa identificar incompletudes cuja superação vem sendo contínua luta social e sindical. A lentidão desse processo em superar suas incompletudes faz com que ao se chegar a uma medida, como a atual inclusão do trabalho doméstico nos direitos trabalhistas, as necessidades e características da sociedade já reclamam por outro modelo protetivo face, por exemplo, às alterações demográficas e a amplitude que segue ganhado a terceira idade.

Entende-se por incompletude da proteção social pública no Brasil a forma racional de "desarranjo estratégico" pela qual ocorre a omissão do Estado em con- 
solidar direitos, reconhecer e prover acessos, gerar a articulação e a completude de atenção entre acessos a serviços de diferentes políticas sociais, o convívio de atenções organizadas por lógicas que não se conectam em princípios e valores, entre outras tantas questões.

Uma delas já assinalada é a de manter as atenções de proteção social em campo fluido entre o público e o privado, o que permite sua manipulação para interesses econômicos do capital. Outra é a de introduzir meios que descaracterizem a demanda de proteção pela "oferta de horizonte em exercer ocupação", que poderá vir a ser rentável, caso frequente cursos, atividades cujo produto possa ser mercadorizado.

\section{Presença do Serviço Social na proteção social}

Os nexos entre Serviço Social e proteção social têm sido considerados na literatura do Serviço Social sobretudo sob três vertentes. A primeira toma a proteção social como campo inerente ao trabalho profissional do assistente social cujo exercício requer preparo especializado, sobretudo para o trato de situações de vitimizações decorrentes de violências, entre outras formas; a segunda toma a proteção social enquanto campo de ampliação e conquista de direitos humanos e direitos sociais na sociedade do capital; e a terceira trata a proteção social, e suas diferentes políticas, como expressões do embuste do capital sobre o trabalho na sociedade de mercado. É principalmente a política de proteção social de assistência social que tem recebido severas críticas, considerada como expressão de um fetiche que sob aparência de atenção mascara os interesses do capital fragilizando todas as outras políticas sociais.

Essa referência à diversidade de compreensão da proteção social, e nela da assistência social, no âmbito do Serviço Social, tem por sentido o registro da diversidade de forças internas na profissão que apresentam forte rejeição em reconhecer a política de assistência social como campo de exercício profissional digno. Não se tem por intenção neste texto, reagir a posições sobre a relação entre Serviço Social e política de assistência social. O hermetismo com que referenciais ideopolíticos são tratados em diferentes análises contrárias ao trabalho do assistente social na política de assistência social, afasta possibilidades argumentativas baseadas em movimentos e lutas postas na mediação do real pela ação profissional. 
Parto da necessidade da análise crítica da sociedade do capital como iluminação dos campos da luta econômico-social pela conquista de Direitos Humanos e sociais na sociedade brasileira, campos de ação do profissional assistente social. É nessa perspectiva que conduzo esta reflexão onde a análise crítica não é imobilizante, e, sim, componente da ação profissional voltada para a conquista social de Direitos Humanos e sociais a todos.

Há que ser superado o entendimento do exercício profissional do assistente social alinhado à condição de analista, identificador de expressões da questão social, o que sem dúvida é um passo necessário, mas que se completa na medida em que o profissional vincula os elementos de análise com a ação concreta a desenvolver em seu campo de ação profissional.

A leitura crítica da proteção social na sociedade do capital, nela inclusa a política de assistência social, não significa negar sua presença e, menos ainda, significa a negação do trabalho do assistente social em seu âmbito.

A proteção social no Brasil está inserida na concepção de seguridade social, isto é, no conjunto de seguranças sociais que uma sociedade, de forma solidária, garante a seus membros. Portanto, a centralidade está no processo histórico de cada sociedade e nele o trânsito pelo qual determinadas condições sociais de dignidade e sobrevivência são asseguradas enquanto um direito social universal. A agenda de situações que são consideradas como desproteções a compor a seguridade social tem diferenciações entre as três políticas sociais.

A previdência social, na condição de seguro social ligado ao trabalho, afiança um valor substituto à remuneração do trabalho em algumas situações em que ocorrem impedimentos ao seu exercício normal. Esse valor substituto recebe a forma de benefício, pensão e aposentadoria cujo acesso é vinculado a regras de tempo de contribuição, idade, grau de agravo, entre outros requisitos. Em algumas situações, o acesso exige parecer de perito. Aqui então se define um campo de trabalho para o Serviço Social. Quanto ao ciclo vital a previdência social tem maior aplicação quando do envelhecimento humano embora sua ação alcance as vicissitudes humanas que impedem o exercício do trabalho regular e exigem a remuneração substituta.

A saúde, política pública de direitos que opera por um sistema único, o SUS tem agenda de cobertura estendida à prevenção, para além da intervenção de aporte clínico, hospitalar ou não, e cirúrgico ambos com aplicação de avanços tecnológicos. Inclui todo o ciclo de vida humano em suas atenções, embora a atenção 
materno-infantil nela permaneça recebendo atenção especial. Como processo de trabalho, a saúde é fundamentalmente relacional, e opera com escuta, acolhida, relações familiares, cuidados, orientações, saberes, cultura, territórios de vivências e conhecimentos científicos.

A assistência social, política pública de proteção social, opera por um sistema único federativo, o Suas, em implantação em todo o território nacional. Como a saúde sua condição de política de proteção social é distinta da forma de seguro social. Organizada em dois níveis de proteção, a básica e a especial, desenvolve sua ação por meio de serviços e benefícios para o acesso de pessoas e famílias demandantes de proteção social face a agravos de fragilidades próprias do ciclo de vida humano, pela presença de deficiências, decorrentes de vitimizações, por violência, por desastres ambientais, pela presença de discriminação, pela defesa da sobrevivência e de direitos humanos violados. Seu processo de trabalho tem centralidade relacional, e opera com escuta qualificada, construção de referências, acolhida, convívio, relações familiares, relações sociais de âmbito coletivo com abrangência territorial, opera oferta de seguranças sociais. $\mathrm{O}$ escopo de suas atenções envolve situações humanas complexas que incluem abandono, violência em variadas faixas etárias, com incidência de gênero e de formas de ocorrência dentro e fora da família, restauração de padrões de dignidade, resgate de vida social de pessoas de diferentes faixas etárias vivendo nas ruas, adolescentes em medidas socioeducativas.

Embora uma pauta considerável de situações demandantes de atenção, através de rede de serviços socioassistenciais de proteção social, se coloque para a política de assistência social, profissionais do SUAS veem sendo requisitados a operar, ainda que pontualmente, em programas de benefícios ou de transferência de renda. A desproteção social na sociedade de mercado se transmuta em renda, mais ainda, em per capita, ou, dito em outros termos, em condição de acesso ao consumo. Essa é uma situação de tensão entre obter segurança de renda e sobreviver em uma sociedade onde a mercadoria exige capacidade de consumo no mercado. Essa tensão presente na dinâmica das atenções de assistência social é uma das questões mobilizadoras do confronto com os direitos socioassistenciais.

Sob trato reiterado já se percorreu neste texto a dualidade que a proteção social adquire na sociedade capitalista uma vez que seu conteúdo pode ser situado sob o campo de antítese de princípios de acumulação. Sob esse entendimento, a luta pelo reconhecimento de Direitos Humanos e sociais no âmbito da proteção social lhe imprime marcas significativas e aproximam o Serviço Social e a direção de seu projeto ético-político desse campo de prática. 
Por evidência que não cabem ilusões quanto à disseminação mágica de consciência humanitária capaz de reverter esse quadro, mas não cabe, por outro lado, dar a questão por perdida. Isto é, uma leitura niilista de que não vale a pena a luta, uma vez que o capital hegemonizado em contexto global sempre condicionará uma resultante negativa sobre o trabalho.

É sob essa perspectiva que a ação profissional do assistente social constrói suas possibilidades de exercício da prática que é, ao mesmo tempo, um contínuo confronto com as reduções que se processam no caminho da igualdade e uma ação que busca estender o mais possível o alcance do direito.

A aproximação do Serviço Social aos campos da proteção social, e da seguridade social, é bem mais recente do que em outros campos de ação como saúde hospitalar, habitação popular, movimentos sociais, gênero, criança e adolescente, entre outros tantos. Isto não significa desconsiderar a inserção do Serviço Social nos IAPS, ou mesmo, após 1974, na Previdência Social considerada a hegemonia histórica dessa área no campo da proteção social.

O que se quer destacar é que o domínio da construção de um campo direcionado para a atenção a fragilidades do ciclo de vida, vitimizações, parecia adquirir um tom residual, talvez puxando mais para um conteúdo terapêutico, pouco entusiasmante para o Serviço Social com forte apelo para a perspectiva histórica e societária. A ação federal na previdência social, na saúde e mesmo na assistência social ocuparam espaço quando do debate ampliado dos rumos dessas políticas, seus princípios, financiamento, a reforma da previdência, a reforma sanitária, a luta pela LOAS, que se poderia também nominar de reforma da assistência social. O processo de formação na graduação orientado para o caráter geral, sem especialização da ação profissional em uma das políticas sociais não gerou também uma provocação maior quanto ao domínio desses campos.

É de se ter presente que em debates, fóruns, congressos a categoria tem expressado sua posição sobre concepção, princípios, alcance, entre outras perspectivas críticas sobre a seguridade social brasileira. Mas ainda é ausente a articulação do conteúdo operado pelo Serviço Social nas três políticas sociais que compõem a seguridade brasileira. Com essa direção aborda-se aqui, no limite de alguns apontamentos, a inserção do Serviço Social nas atenções das políticas sociais que compõem a seguridade social em busca de pontos de articulação e, com eles, a superação do atual afastamento, ausência de nexos, presença de fragmentação.

Dar força à seguridade social supõe a unificação de propósitos e lutas, o que poderia começar a ocorrer pela aproximação, desde a base, de profissionais que 
trabalham nessas três políticas de seguridade social, e, não raras vezes, são eles avizinhados por territórios de trabalho comum.

O Serviço Social no interior da Previdência Social apresentou um circuito de declínio ao longo dos anos. A Previdência Social no Brasil já adotou modelo abrangente que envolvia mais do que o trabalho, com programas para habitação e saúde do trabalhador e de sua família. Operava sob formato relacional com os previdenciários, não se restringia a administração de benefícios. Nesse momento congregou profissionais do Serviço Social, sendo, campo de estágio para formação profissional. A reforma da Previdência Social em 1974 e a sequente unificação dos institutos previdenciários (IAPs) provocou alterações no âmbito do Serviço Social, e seu campo foi sendo reduzido a partir da limitação da ação da previdência a administração de benefícios de um seguro público.

Desde 1996, quando do início de operação do Benefício de Prestação Continuada, o BPC, foi decidido pela Presidência da República que não seria reforçada a capacidade gerencial da burocracia da assistência social para operá-lo, uma vez que o modelo então predominante era o do Comunidade Solidária. Contrato administrativo entre a Secretaria Nacional de Assistência Social - SNAS então vinculada ao Ministério da Previdência e Assistência Social e o INSS decidiu que esse, mediante pagamento, permaneceria gerindo o BPC, em suas agências, assim como seu antecessor o RMV - Renda Mensal Vitalícia. Esse tratamento aparentemente de gestão administrativa vem significando de fato, o declínio da gestão do BPC sob a lógica de proteção da assistência social mantendo-o sob a lógica de seguro social, qualificando-o como amparo assistencial ou benefício assistencial. Entende-se que essa operação, do ponto de vista administrativo, consiste em "uma terceirização entre órgãos públicos" que dá vida à fragmentação.

Essa situação é realmente curiosa. A assistência social desempenha uma das funções governamentais, nominada em linguagem governamental, sobremodo a orçamentária, como função programática. O maior gasto federal no orçamento público na Função programática 8 - número que compete à assistência social - é destinado ao BPC. Seu custeio é compulsório e atinge em 2013 a 33 bilhões de reais. Todavia, embora o BPC seja sustentado com recurso financeiro da assistência social, profissional de Serviço Social que opera o benefício pertence aos quadros da Previdência Social, em especifico do INSS. Ele atua nas agências do INSS como perito nas solicitações de BPC para pessoas com deficiência. Não há articulação entre a ação das agências do INSS e o SUAS, não há vínculos, nem territoriais, entre os profissionais dos CRAS e os das agências do INSS. 
As agências do INSS estão cada vez mais limitadas à estrita administração de benefícios operados através de sistemas informacionais que tornam dispensável o relacionamento humano, uma vez que a inflexibilidade ou a homogeneidade de regras de operação, requeridas pelos sistemas informacionais, não permite a incorporação de diferenças ditadas pela particularidade de necessidades. ${ }^{4}$ É possível que a flexibilidade ainda permaneça junto a administrações de previdência destinadas a grupos seletos, como militares das Armas nacionais e da polícia militar, servidores públicos, bancários do sistema público, como a PREVI, mantenham campo de trabalho para assistentes sociais uma vez que ainda possam ter algum grau de flexibilidade na proteção social.

A inserção do Serviço Social no âmbito de serviços de saúde se dá no Brasil ainda na década de 1940 do século passado. Em 1948, foi atribuída importância ímpar à instalação do Serviço Social na dinâmica de gestão do Hospital das Clínicas a forma inédita de hospital público de excelência com atração de pacientes de âmbito nacional e internacional. Ao Serviço Social foi atribuída a gestão da triagem socioeconômica dos demandatários. Não se configurava, ainda, o direito universal à saúde. Só após 40 anos com a CF-88 é que este direito configura a universalidade de atenção o que retira toda e qualquer necessidade de prova de meios para que o cidadão seja atendido em um serviço de saúde pública. ${ }^{5}$ Claro que aqui não estão referidos os próprios meios efetivos da área de saúde para atender o cidadão, mas esta questão é de natureza diversa pelo seu caráter avaliativo de serviços prestados.

A presença do Serviço Social no Sistema Único de Saúde — SUS tem variações decorrentes da divisão do trabalho profissional adotada pelo serviço prestado. A entrada do profissional pode ser vertical ou horizontal. Em ações programáticas, horizontais, o assistente social compõe equipes interprofissionais direcionadas para a saúde da mulher, a saúde da família. É de se dar relevância a inserção do Serviço Social nos NASF — Núcleos de Apoio à Saúde da Família e na Residência Multiprofissional em Saúde. Na atenção hospitalar, a depender do volume e tipos de especialidades dos leitos, o profissional de Serviço Social pode ter inserção por

4. É importante ter claro que a isonomia da igualdade prescinde e nega espaço à diversidade da equidade em que o Serviço Social tem maior campo de ação.

5. A perplexidade está em que o Serviço Social instalado em hospitais de universidades públicas, mantidos com orçamento público, ainda pratiquem neste terceiro milênio a seleção socioeconômica de 1948 como critério de acesso a demandatários de atenção e em pleno confronto com o direito universal à saúde afiançado constitucionalmente. Aliás, é bom ter claro que o domínio do procedimento de seleção econômica está posto como atribuição do profissional assistente social na descrição das funções das profissões. 
especialidades, clínicas e/ou cirúrgicas, ou manter a atenção genérica voltada para relações entre o paciente e sua família e/ou suas condições externas para manutenção de seus cuidados de saúde. É de se referir a presença nada trivial de assistentes sociais em cargos de direção na gestão da saúde básica ou preventiva.

O campo do Serviço Social na assistência social, de mais recente estruturação pela implantação do SUAS — Sistema Único de Assistência Social, a partir de 2005 , tem provocado forte mudança no perfil de gestão dessa área que se estrutura em todos os entes federativos, vale dizer em mais de 5580 unidades gestoras, com capacidades, abrangências e responsabilidades diferenciadas.

A inserção do Serviço Social na assistência social tem percurso diverso ao das demais políticas componentes da seguridade social. A categoria, sob diferentes formas, se envolveu em luta de 15 anos seguidos para poder conquistar em 2004 a aprovação de Política Nacional de Assistência Social e no ano seguinte, 2005, a aprovação da implantação do SUAS — Sistema Único de Assistência Social.

A introdução da política de assistência social no âmbito da seguridade social foi menos resultante de uma proposta articulada nessa direção, até porque inexistiam movimentos pró-seguridade social, e mais para ajustar a situação de benefícios não contributivos que permaneciam sob gestão da previdência social e serviços de saúde que permaneciam sob gestão da LBA, a fundação federal com pouco mais de 45 anos naquele momento que catalisava iniciativas e recursos federais para essa área.

Esta primeira fase de institucionalização da assistência social como uma das áreas governamentais responsáveis pela proteção social apareceu como um mix de iniciativas institucionais pró e contra a afirmação da assistência social como política pública de proteção social. Nele se podem destacar:

a) a grande fusão que correspondeu à busca de unidade de trato às competências dispersas alterando o que se apresentava de forma difusa e confusa.

a.1) no plano federal, a fusão significou exportar da previdência para a assistência social benefícios que não eram contributivos (RM e benefícios eventuais) e lhes atribuir uma nova regulação; extinguir a LBA e seus resquícios assistencialista, possibilitando que a assistência social ocupasse espaço na gestão direta pela dinamização da Secretaria de Assistência Social do MPAS, que assumiu a gestão dos serviços continuados que estavam na LBA (SAC-PAC). 
a.2) fase $\boldsymbol{C P F}$ - introdução no órgão gestor da assistência social dos ente federativos estaduais e municipais, marcas de gestão democrática pela presença de conselho, plano e fundo, dando início ao processo de construção da unidade nacional, a política pública e a realização das primeiras conferências municipais, estaduais e nacional.

b) o contra movimento gerado em janeiro de 1995 quando a LBA é extinta e colocado em seu lugar o Conselho da Comunidade Solidária um modelo de gerência social que fortalecia as organizações privadas (marco legal do terceiro setor - criação das OCIPS) através de uma gestão paralela à Secretaria de Assistência Social do MPAS, como a anterior LBA. Essa decisão esgarçou a possibilidade da gestão unitária da proteção social. Foram desenvolvidas diversas propostas de subsídios financeiros à população na forma de bolsa, vales, entre outros, geridos por diversos ministérios. Foram criados empecilhos para a realização de Conferências Nacionais.

c) articulação unitária de forças sociais e políticas para implementação da Loas (frente parlamentar, frente de prefeitos, movimentos de articulação da categoria dos assistentes sociais) centrada em instituir o financiamento federativo da política, fortaleceu a demanda dos entes federativos pelo financiamento federal da assistência social e impeliu (politicamente) a necessidade de implementação de normas nacionais reguladoras das transferências de recursos fundo a fundo. As palavras de ordem dessa articulação centravam-se em denunciar o modelo de convênios adotado para as transferências aos municípios ao invés de adotar o modelo de transferência fundo a fundo; denunciar a descontinuidade do financiamento federal como ocorria na velha LBA, o que impedia manter serviços em operação e permanecia com a lógica de projetos circunstanciais; denunciar o controle pela CND da operação de transferências financeiras entre órgãos públicos impedindo sua efetivação; exigir a fixação de um percentual mínimo fixo no orçamento público para o custeio da política.

Para além dessas alterações demarcadas pela implementação na gestão da assistência social de categorias de política pública provedora de atenções (e não mais política de fomento a entidades sociais) a exigência da efetivação do controle social e da democratização da gestão, com a presença de usuários nos conselhos 
gestores, vem se mostrando como campo de luta contínua, juntamente com a preocupação com o expurgo das velhas formas conservadoras de gestão que distanciavam a assistência social do campo democrático da política pública e a vinculavam à permanência do patrimonialismo de primeiras-damas.

O Suas, sistema único e nacional de proteção social do campo da seguridade social em implantação, tem desafios sérios a enfrentar.

O primeiro deles é a baixa referência na sociedade sobre o conteúdo a ser assegurado pela proteção social não contributiva. Essa frágil clareza percorre o âmbito do Serviço Social, introduzindo inclusive questionamentos se a assistência deveria ou não ser uma política pública, ou ainda, se deveria ter abrangência maior do que a atenção a residualidades.

O campo da assistência social, assim como o da saúde, não distingue os cidadãos como inseridos, ou não, em trabalho formal ou informal. Para ambas políticas o direito a ter uma necessidade atendida é primordial, independentemente de sua situação de emprego.

A assistência social, assim como a saúde, como já foi salientado ao longo desta reflexão, não se limita à proteção social ao ciclo de vida ou à análise da renda per capita de uma família. Enquanto política de proteção social com matricialidade sociofamiliar é a relação entre provedores e dependentes em uma família (a razão de dependência), a rede de vínculos sociais que a família e seus membros mantêm com a parentela, amigos, vizinhos, associações, somadas às possibilidades concretas de oferta de acessos, com que a família conta, nas políticas públicas no território onde vive, que estabelecem sua capacidade de reagir às desproteções sociais que enfrenta, ponderado sempre os agravos das necessidades de proteção dos membros que compõem a família.

A assistência social, assim como a saúde, opera para além do indivíduo, isto é, introduz a família como núcleo de proteção social. Não ocorre, todavia, um caminho de articulação entre as duas políticas quanto às implicações da inclusão da família no âmbito da proteção social brasileira, o que deveria ser tematizado de forma mais alargada possibilitando sair de uma discussão um tanto sem horizonte, no âmbito da assistência social, que se ocupa da crítica do trabalho com famílias como uma reedição do familismo, ou da guetização de responsabilidades de proteção social ao âmbito familiar.

Um segundo desafio para o Suas é o da concretização da sua responsabilidade estatal como efetiva proteção social. Essa construção vem sendo objeto de 
contínua luta que tem, emblematicamente, na desvinculação do CNAS (Conselho Nacional de Assistência Social) da função cartorial de concessão a uma organização social, em várias áreas de ação, do mérito da filantropia ou de ser beneficente por atender de forma gratuita a pobres, uma das marcas de ruptura fundante do ingresso da assistência social na arena das políticas sociais públicas.

Esse desafio é, antes de mais nada, uma disputa de projeto político quanto à efetivação da assistência social enquanto política estatal. Há em curso, e já experimentado pelo modelo Comunidade Solidária, a concepção de que as organizações sociais sem fins lucrativos estariam mais preparadas para produzir atenções de assistência social com qualidade do que os agentes institucionais do Estado ${ }^{6}$. Pode-se afirmar a partir desses dados que a gestão por ONGs de serviços sociais públicos está impulsionando a precarização da remuneração do trabalho profissional.

A defesa do modelo de parcerias, baseada na concepção de que o papel do Estado é o de fomento de ONGs e não de ação direta na assistência social, isto é, a permanência do modelo de subsidiariedade, de costas para o alcance de direitos sociais, é fundado numa proposta de trabalho com pequenos grupos, com indivíduos e não com garantias ou certezas de proteção social a todos. ${ }^{7}$

Um terceiro e enorme desafio do Suas é o de não configurar a assistência social, enquanto política pública, responsável pela atenção ao pobre ou a pobreza criando a velha modalidade de segregação que estabelece um espaço apartado para atenção dos que têm menos renda. Ações em relação ao pauperismo devem ser operadas sob modalidade de gestão inter-setorial uma vez que pobreza é uma questão multidimensional que tem suas raízes na opção do modelo econômico que, ao

6. Resultados da Fasfil - Mapeamento das Fundações Privadas e Associações sem Fins Lucrativos, realizado pelo IBGE, Ipea, com a presença da Abong e do Gife analisados no movimento de 2010 face a 2006, mostram que organizações dedicadas à educação infantil cresceram 43,4\% no período; em compensação, nelas os salários médios reduziram em 19\%. Na saúde ocorreu, no período, uma redução de 5,8\% das organizações dedicadas a essa atividade e uma redução de 5\% no salário médio. Na assistência social, a ampliação nacional de organizações foi de 1,6\% e a redução do salário médio foi de $11 \%$.

7. Os argumentos em que se assenta essa proposta, de acordo com Cardoso (2005), são: a capilaridade, considerando que as ONGs têm mais facilidade em chegar aos rincões onde não há Estado, e assim elas poderiam atuar em contextos marcados pela informalidade, sendo esta sua segunda grande característica - a ONG não tem obrigações como as estatais com o legal e formal; a terceira característica é a experimentação, isto é, sua desobrigação com a totalidade permite ser mais assertiva com a particularidade de uma realidade; a quarta é a capacidade de articulação com a realidade local, isto é, não tem o endurecimento de uma agência pública, podendo desenvolver maior mobilização e participação; e, por último, a representatividade, considerando a ONG um canal mediador enquanto um sujeito coletivo. 
invés de ser redistributivo, é concentrador de riquezas. É necessário confrontar a permanência de usos e costumes conservadores que permanecem na política de assistência social quando orienta o acesso pela renda dos usuários, e não pela necessidade. O preenchimento do instrumental do Cadastro Único nem sempre permanece nos CRAS, até por quê a obtenção do NIS tornou-se obrigatória para acesso a várias políticas sociais, transformou-se em um documento de acesso para todos cuja renda se situe em até 3 salários mínimos. O NIS é necessário para ingresso em programas habitacionais, obtenção de tarifa social no uso de energia, entre outras aplicações em programas governamentais.

Recai para os profissionais dos CRAS a gestão do não cumprimento de condicionalidades pela família beneficiária de transferência condicional de renda, programa cuja cobertura no país é de cerca de 14 milhões de famílias. A inadequação da assistência social ter que responder pelas fragilidades da política de saúde e de educação é um procedimento considerado inadequado, inclusive pela sanção ao beneficiário que essa medida supõe. A gestão não relacional com que o programa federal de transferência de renda é gerenciado afasta qualquer operador de sua gestão. Opera à distância, por gestão mecânica de rede de programas e computadores, orientada a se desenvolver sob a "anti-presença" e "anti-interferência" de profissional. Quem recebe em qualquer um dos 5565 municípios, um cidadão requerente de Cadastro não tem qualquer poder decisório quanto a concessão do benefício, nem sabe se a família que o procurou para cadastramento será ou não beneficiária.

\section{Desafios da proteção social no terceiro milênio}

O horizonte da proteção social brasileira exige a integração das três políticas de seguridade social. Esta perspectiva significa construir linhas de conexão entre os serviços das três políticas desde a base, com uma agenda que inclua a superação das questões que estão colocadas em cada uma dessas políticas.

Os resultados obtidos até o momento quanto à maior formalização do trabalho, a revalorização do salário mínimo são, sem dúvida, conquistas significativas, todavia elas convivem com a alta rotatividade dos trabalhadores que em 2010 atingia a $53,8 \%$ da força de trabalho formalizada. De acordo com informe da CUT, 5,5\% dos estabelecimentos empregadores são responsáveis por $2 / 3$ das demissões. 
Essa perversa situação exige que o tempo de seguro desemprego seja considerado como tempo de contribuição, pois de outra forma temos a vida do trabalhador empurrada para mais anos até se aposentar. Há aqui um debate quanto à alocação do seguro desemprego, de natureza contributiva, no âmbito da previdência e não do FAT.

Enfim há uma pauta de questões que incluem a expansão do tempo sob a aposentadoria, as mudanças nas estruturas familiares, a desvinculação entre formação e emprego principalmente para o jovem.

Esse conjunto de questões requer uma revisão do horizonte da inter-relação das três políticas em ambiente da seguridade social. É preciso criar uma frente de defesa, o que demanda estratégias de luta em sua efetivação. Não é uma causa perdida o horizonte da seguridade social, e ela será mais visível, e factível, quanto mais elos forem estabelecidos entre as três políticas que dela fazem parte.

Recebido em 12/8/2013 - Aprovado em 19/8/2013

\section{Referências bibliográficas}

BOSCHETTI, Ivanete. Assistência social no Brasil: um direito entre originalidade e conservadorismo. 2. ed. Brasília: UnB, 2003.

CARDOSO, Ruth. Fortalecimento da sociedade civil. In: IOSCHPE, Evelyn B. (Org.). Terceiro Setor: desenvolvimento sustentado. 3. ed. Rio de Janeiro: Paz e Terra, 2005. p. 7-12.

CASTEL, Robert. A insegurança social: o que é ser protegido. Petrópolis: Vozes, 2003.

CONSELHO FEDERAL DE SERVIÇO SOCIAL. O trabalho do/a Assistente Social no Suas: Seminário Nacional. Conselho Federal de Serviço Social. Brasília: CFESS, 2011.

COUTO, Berenice Rojas. O direito social e a assistência social na sociedade brasileira: uma equação possível? 2. ed. São Paulo: Cortez, 2006.

GOMES, Maria do Rosário C. S. Nacionalização da política de assistência social e governos estaduais no Brasil: o caso do Estado de São Paulo. Tese (Doutorado em Serviço Social) — Pontifícia Universidade Católica, São Paulo, 2008. 
FAGNANI, Eduardo. Política social do Brasil (1964-2002) entre a cidadania e a caridade. Tese (Doutorado em Economia) — Unicamp, Campinas, 2005.

FASFIL. As fundações privadas e associações sem fins lucrativos no Brasil: 2010. Estudos e Pesquisas, Informação Econômica, Rio de Janeiro, IBGE, n. 20, 2012.

JACCOUD, Luciana. Proteção Social no Brasil: debates e desafios. In: . Concepção e gestão da proteção social não contributiva no Brasil. Brasília: MDS/Unesco, 2009. p. 57-86. MESTRINER, Maria L. Assistência social e seguridade social: oposições e aproximações. Dissertação (Mestrado em Serviço Social) — Pontifícia Universidade Católica, São Paulo, 1992.

MOTA, Ana Elizabete. O mito da assistência social: ensaios sobre Estado, política e sociedade. 2. ed. São Paulo: Cortez, 2008.

PEREIRA, Potyara. A assistência social na perspectiva dos direitos: crítica aos padrões no Brasil. Brasília: Thesaurus, 1996.

SILVA, Ademir A. A gestão da seguridade social brasileira: entre a política pública e o mercado. São Paulo: Cortez, 2004.

SPOSATI, Aldaíza. Modelo brasileiro de proteção social não contributiva: concepções fundantes. In: Concepção e gestão da proteção social não contributiva no Brasil. Brasília: MDS/Unesco, 2009. p. 13-56.

. Proteção e desproteção social na perspectiva dos direitos socioassistenciais. In: CONFERÊNCIA NACIONAL DE ASSISTÊNCIA SOCIAL, 7., Brasília, CNAS, 2007.

VIANA, A.; ELIAS, P.; IBAÑEZ, N. Proteção social: dilemas e desafios. São Paulo: Hucitec, 2005. 